\title{
A PRODUÇÃo DO CONHECIMENTO PSICOLÓGICO- PSIQUIÁTRICO EM SAÚDE MENTAL: CONSIDERAÇÕES A PARTIR DE UM TEXTO EXEMPLAR
}

\author{
Aline Frollini Lunardelli Lara ${ }^{1}$ \\ Universidade de Mogi das Cruzes - SP
}

\begin{abstract}
Este trabalho discute a relação entre ideologia e o conhecimento produzido na Psiquiatria, a fim de desvelar o que está oculto em um texto considerado científico. O material analisado trata da prevenção primária de distúrbios psíquicos que produzem "desajustamento social". A análise centra-se no próprio conceito de prevenção como ideologia, numa perspectiva crítica que busca as lacunas que garantem e legitimam o poder político dos que detêm o conhecimento hegemônico na área da saúde mental.
\end{abstract}

Descritores: Psiquiatria. Psicologia. Ideologia. Saúde mental. Ajustamento social.

Tos cursos de graduação em Psicologia, os alunos entram em contato 1 com diversas abordagens teóricas que fundamentam a prática do profissional psicólogo. Como regra, essas teorias fazem parte do discurso competente, na acepção de Chauí (2001b), ou seja, de um conhecimento que, por ser produzido em determinados lugares sociais e pelos únicos autorizados a

1 Psicóloga, Mestre em Psicologia Escolar e do Desenvolvimento Humano pelo Instituto de Psicologia - USP. Docente do curso de Pedagogia da Universidade de Mogi das Cruzes - SP. Endereço eletrônico: alineflunardelli@uol.com.br. Endereço para correspondência: Avenida Otacílio Tomanik, N. ${ }^{\circ}$ 1054, Apto. 64, Jardim Bonfiglioli, CEP 05363-101, São Paulo-SP. 
falar sobre os fenômenos do mundo físico, social e psicológico, tornam-se hegemônicos e silenciam outras falas.

Uma aparente diversidade teórica esconde fundamentos filosóficos muitas vezes comuns. No entanto, uma questão que pouco é levantada e sobre a qual pouco se reflete nesses cursos é a das bases epistemológicas e ético-políticas da ciência psicológica. Quanto ao compromisso político, nem todas as concepções psicológicas têm como foco a questão da autonomia dos indivíduos, das possibilidades de resistência à opressão e à manipulação das consciências nas sociedades contemporâneas. Ao invés disso, muitas destas concepções nascem e se desenvolvem a partir de objetivos essencialmente contrários à possibilidade de humanização dos homens. Por isso mesmo, seu compromisso político precisa ser explicitado.

Este artigo analisa um texto adotado em cursos de formação em Psicologia: “Um Modelo Conceptual para Prevenção Primária”, capítulo do livro Princípios de Psiquiatria Preventiva, de Gerald Caplan (1980), publicado pela primeira vez em 1964. Caplan, psiquiatra, na época da publicação do livro, era professor da Escola de Saúde Pública e Diretor do Programa de Saúde Mental Comunitária da Universidade de Harvard. O livro é fruto de suas experiências em ambulatórios psiquiátricos e hospitais gerais, bem como de sua participação em programas de Psiquiatria comunitária e como consultor de programas comunitários de saúde pública e mental em mais de dez países. Segundo Felix (1980),

Este livro é não só uma cartilha para o assistente comunitário de saúde mental - é uma Bíblia. Deve ser lido por todos os residentes psiquiátricos e profissionais ligados à saúde mental, bem como pelos que se encontram em treinamento para essa profissão e por quantos estão empenhados na elaboração de programas comunitários de saúde mental. (p. 9)

A reflexão terá como ponto de partida os conceitos de prevenção, ideologia e de discurso competente. 
A Produção do Conhecimento Psicológico-Psiquiátrico em Saúde Mental...

O texto de Caplan organiza-se ao redor de três eixos: conceituação de prevenção primária; conceituação de crise como explicação para as perturbações mentais; desenvolvimento de um modelo de prevenção primária a partir do conceito de crise.

A proposta do autor é prevenir momentos de crise e intervir nestas situações, com o objetivo de evitar que o transtorno mental se instale e se cronifique. Para desenvolver esta proposta, ele sugere a prevenção primária, na qual se trabalha com as dimensões física, psicossocial e sociocultural da vida das pessoas.

À primeira vista, o texto pode deixar a impressão de que estamos tratando de um modelo de prevenção em saúde mental que considera não apenas o indivíduo portador da enfermidade, mas também todos os aspectos sócio-culturais ou a unidade biopsicossocial na produção da doença mental. Entretanto, uma análise crítica do material revela que o indivíduo continua sendo o locus da produção da saúde ou da doença, do sucesso ou do fracasso pessoal-social, como será visto a seguir.

No decorrer do texto, as definições de saúde e de doença referem-se à possibilidade de adaptação ou desadaptação individual: "Esta abordagem baseia-se no pressuposto de que muitas perturbações mentais resultam de inadaptação e desajustamento, e que, pela alteração do equilíbrio de forças, é possível conseguir uma adaptação e um ajustamento saudáveis” (Caplan, 1980, p. 42).

Para determinar os fatores que levam ao aparecimento da doença mental, o autor compara características da população doente e da população sadia:

Se a pessoa nasceu num grupo favorecido em uma sociedade estável, seus papéis sociais e as mudanças esperadas destes ao longo de sua vida irão proporcionar-lhe oportunidades adequadas para um saudável desenvolvimento da personalidade. Se, por outro lado, a pessoa pertence a um grupo desfavorecido ou sociedade instável, poderá encontrar seu progresso bloqueado e ser privada de desafios e oportunidade. Isso terá um efeito negativo em sua saúde mental. (p. 47, grifos nossos) 
As palavras destacadas fazem parte de um articulado ideário que localiza o sucesso ou fracasso social numa classe específica, causadora e propagadora de distúrbios mentais e sociais: uma classe abstratamente designada como "desfavorecida”.

O termo prevenção, de origem médica, é utilizado com freqüência em espaços especializados e leigos. No dicionário, prevenir é: “antecipar; preparar; chegar antes de; evitar; prever; dispor de modo que evite dano ou mal; impedir que se realize; dizer ou fazer antes que o outro diga ou faça; realizar antecipadamente; ir ao encontro de; atalhar; avisar, informar com antecedência; influenciar; dispor; preparar-se; precaver-se” (Ferreira, 1963, p. 972). Prevenção remete ao verbo prever, que significa "ver antecipadamente; calcular; pressupor; predizer; conjeturar; profetizar; fazer conjeturas; reflexionar; calcular” (p. 972).

A prevenção primária, de acordo com Caplan (1980), implica em lidar com algo que ainda não aconteceu, com o objetivo de antecipar um mal para que ele possa ser evitado. Em resumo, alguns indivíduos podem possuir características responsáveis por seu adoecimento. Além disso, saúde mental é adaptação dos indivíduos. Caberia ao psiquiatra a manipulação de algumas circunstâncias de vida da população para efetivar tal adaptação.

Os elementos constitutivos da Psiquiatria preventiva estão presentes em todo o texto de Caplan: as mudanças do objeto de estudo, o objetivo do tratamento, o sujeito a ser tratado, quem é o responsável pela cura e o novo espaço de atuação dos profissionais de saúde mental. Deve-se atuar, de acordo com o autor, na comunidade, saindo dos consultórios privados para atender a população, pois o foco de intervenção não é o indivíduo. Tem-se por objeto promover a saúde mental e as equipes de profissionais habilitados são responsáveis por isto.

É importante ressaltar que, neste modelo, os fundamentos dos conceitos de prevenção, de saúde $\mathrm{x}$ doença mental estão na harmonia do sujeito visto como unidade biopsicossocial e, portanto, na adaptação da população aos modelos de produtividade e obediência, garantindo sua condição saudável. 
Se, antes, falava-se de adaptação x desadaptação dos indivíduos, o discurso passou a ser com relação a muitas pessoas. É necessário, assim, para o autor, intervir nas comunidades, com o objetivo de impedir, evitar, que as condições perniciosas destas se manifestem causando a doença mental.

A adaptação e o ajustamento dos indivíduos seriam necessários para que se evitasse a doença mental. O modelo da Psiquiatria preventiva conseguiria, trabalhando com toda a população e não apenas com alguns indivíduos, garantir que doenças mentais fossem evitadas em grande escala. Vale ressaltar que o compromisso ideológico-político das idéias psiquiátricas, representadas pelo texto de Caplan e pela noção de prevenção, não se refere à promoção da saúde mental de todos os indivíduos, mas somente daqueles que já possuírem condições favoráveis para que isto aconteça. Os trechos a seguir ilustram as intenções da proposta do autor:

O primeiro, que inclui atributos tais como idade, sexo, classe sócio-econômica e grupo étnico, não pode ser manipulado, porquanto envolve, por assim dizer, fatores do destino individual (Caplan, 1980, p. 41, grifos nossos).

Certos indivíduos podem ter uma posição tão afortunada ou antecedentes tão privilegiados que, mesmo sem o nosso programa, não cairiam doentes. Outros indivíduos podem ser tão desfavorecidos por sua situação idiossincrática que nenhuma melhoria do quadro comunitário geral seria suficiente para impedir que eles adoeçam. (p. 44, grifos nossos)

Quanto mais rica for sua herança cultural, mais complexos serão os problemas que a pessoa terá provavelmente sido ensinada a dominar. Quanto mais estável for sua sociedade, mais provável é que esta a tenha dotado de instrumentos perceptivos, recursos para resolver problemas e todo um conjunto de valores que a guiem sempre que tenha de enfrentar as dificuldades da vida. Por outro lado, sociedades em transição - e isto aplica-se a muitas em nossa era atual de rápida transformação tecnológica - têm escassas probabilidades de desenvolver métodos bem-ensaiados para lidar com novos problemas com que um indivíduo se defronte, e este ver-se-á obrigado a confiar mais em seus próprios recursos. (p. 47)

De acordo com Caplan, são os momentos de crise psicológica que podem desequilibrar a condição de saúde dos indivíduos. Crises podem ser “mudanças agudas do padrão de comportamento que ocorrem de tempos em tempos no transcurso da vida de uma pessoa” (p. 49). 
À crise é também associada, segundo o autor, a idéia de descontinuidade, ruptura no padrão de funcionamento do sujeito. Ela pode trazer ao indivíduo uma oportunidade de crescimento da personalidade ou um perigo de crescente vulnerabilidade ao distúrbio mental.

A prevenção é necessária para que se neutralizem as condições perniciosas que determinam a doença mental. Neste sentido, a pessoa em crise pode ser uma dessas condições e é necessário “trabalhar” com ela. É preciso, entretanto, que profissionais especializados sejam os responsáveis pela cura, pois os leigos geralmente estão em crise. De acordo com o autor,

Quanto mais sensível e talentosa for tal pessoa em questões interpessoais, mais potente ela pode ser como foco patogênico na comunidade, e mais pessoas em crise ela empurrará na direção errada. Acode-nos à mente a analogia com um agente portador de doença. (p. 64)

A análise do modelo de prevenção primária de Caplan (1980) remetenos à história da Psiquiatria no Brasil. Segundo Costa, a história da Psiquiatria é a história social das idéias psiquiátricas. Esta não pode ser compreendida sem o jogo de interesses políticos e ideológicos que a constituem. Isto significa que

enunciamos nossas "doutrinas científicas" sempre a partir de quadros prévios de interesse (Marx-Habermas); ou de determinados jogos de linguagem (Wittgenstein); ou de determinados jogos de verdade (Michel Foucault); ou de determinados sistemas de convicções sociais, onde realizamos aquilo que utilmente desejamos, em um dado momento histórico (Richard Rorty); ou de determinados sistemas de dominação, onde o instituinte é reificado em instituído, por força dos interesses de classe (Marx-Merleau-Ponty-Lefort-Marilena Chauí), ou enfim, de determinadas configurações imaginárias, que direcionam o saber, em função do narcisismo de pequenas diferenças (Freud) etc. (Costa, 1989a, p. 11, grifos originais)

As idéias psiquiátricas, de acordo com o autor, foram produzidas ao longo da história com compromissos político-ideológicos distantes da problemática da saúde mental. Isto pôde ser observado nos três momentos pelos 
A Produção do Conhecimento Psicológico-Psiquiátrico em Saúde Mental...

quais passou a Psiquiatria no Brasil: o do discurso organicista, o preventivista e o psicoterápico.

No primeiro momento, situado na década de 30, buscou-se encontrar os elementos orgânicos constitutivos dos indivíduos como explicação para os transtornos mentais. Foi a época das noções de higiene psíquica e racial, na qual as práticas eugênicas triunfaram. Acreditava-se que existia uma natureza humana e a decifração das leis de hereditariedade permitiriam a regeneração dos doentes mentais.

A Psiquiatria preventivista, da década de 60 e, mais fortemente, da década de 70, trouxe como proposta a possibilidade de retirar os atendimentos dos consultórios privados e dos asilos para levá-los à comunidade. Seu objeto de estudo era a saúde mental e não a doença, seu objetivo era a prevenção da doença mental, o sujeito de tratamento passou a ser a coletividade e não mais os indivíduos, os profissionais não eram somente os psiquiatras, mas as equipes comunitárias, e o espaço de tratamento passou a ser a comunidade. Um novo conceito de personalidade também foi adotado; o indivíduo tornouse a unidade biopsicossocial.

Já o discurso psicoterápico, está presente na atualidade, propondo o tratamento individualizado, de volta aos consultórios, agregando os conhecimentos da Psicologia, na multiplicidade de seus campos teórico-práticos.

Os dois primeiros discursos, organicista e preventivista, serão mais detalhadamente analisados. A princípio, apenas o momento da prevenção poderia ser foco de nossa atenção, uma vez que o texto de Caplan se refere primordialmente a este assunto. Porém, como se verá, o discurso organicista, que parecia superado, também está explicitamente presente na proposta desse autor.

Iniciemos pela prevenção. De acordo com Costa (1989b), a Psiquiatria preventiva deve ser compreendida também como um discurso ideológico porque veio atender às necessidades de prestígio para uma classe - os psiquiatras - que perdiam espaço para a Sociologia e para a Psicologia, entendendo a doença mental como uma doença do psiquismo e não do soma. Além disso, a prática destas ciências não se fundamentava exclusivamente nos 
métodos das ciências naturais, como a Psiquiatria, que foi perdendo o lugar de sua especificidade.

O modelo de atuação da Psiquiatria preventiva foi, então, adaptado, principalmente, da Sociologia. O próprio conceito de unidade biopsicossocial teve esta origem. Os indivíduos passaram a ser analisados a partir desta síntese que deveria se constituir de forma harmoniosa, determinando que a saúde estaria relacionada à adaptação das dimensões biológica, psicológica e social.

A idéia de prevenção da Psiquiatria preventiva é de inspiração nitidamente sociológica. Foi porque a Psiquiatria tomou emprestado à sociologia o critério adaptação-desadaptação, como meio de avaliação do comportamento normal e patológico, que a idéia de prevenção tornou-se possível. Todavia, para que o conceito sociológico se tornasse compatível com o conceito psicológico, também contido na noção de unidade biopsicossocial, este último teve que sofrer reduções e mutilações até se conformar completamente ao primeiro. (Costa, 1989b, p. 30, itálico original)

O texto de Caplan, assim, insere-se no auge do discurso preventivista, analisado criticamente por Costa (1989b). Mas, por que foi assinalado que é também representativo do discurso organicista, teoricamente, abandonado há muito tempo? Talvez, uma única citação do autor justifique esta indagação:

\footnotetext{
Vale assinalar que aquilo a que os epidemiologistas chamam "fatores do hospedeiro", notadamente as qualidades dos membros de uma população que determinam sua vulnerabilidade ou resistência às tensões ambientais, são constituídos por dois grupos de atributos. O primeiro, que inclui atributos tais como idade, sexo, classe sócio-econômica e grupo étnico, não pode ser manipulado. O segundo grupo, incluindo atributos tais como a força do ego, a habilidade para a solução de problemas e a capacidade para tolerar a angústia e a frustração, é habitualmente fixo, mas pode ter sido modificado no passado, mediante uma alteração da experiência do indivíduo ou de seus pais. Fatores cromossômicos situam-se na fronteira entre esses dois grupos. Quando soubermos mais a seu respeito, talvez seja possível intervir eugenicamente para modificar padrões genéticos numa população e, assim, aperfeiçoar a dotação constitucional fundamental de seus membros. (pp. 41-42, grifos nossos)
} 
A Produção do Conhecimento Psicológico-Psiquiátrico em Saúde Mental...

Neste trecho, verifica-se de forma clara e nada sutil qual seria a finalidade última do autor caso a Psiquiatria estivesse de posse de tais conhecimentos para sanar as doenças mentais da população. Parece que estamos diante de questões apresentadas por psiquiatras do final do século XIX e início do século XX, analisadas por Schwarcz (2002).

A autora apresenta, no capítulo referente às Faculdades de Medicina do país do início do século XX, a expectativa da Psiquiatria em regenerar a sociedade brasileira, por meio de uma depuração racial, utilizando-se de programas eugênicos. A doença mental, vista como um problema social, deveria ser tratada pelos médicos. Assim, a Medicina passa a ter um importante papel político (entendido como exercício de poder numa sociedade dividida, desigual e injusta) no cenário brasileiro.

Naquela época, de acordo com Schwarcz (2002), havia a associação linear entre a doença mental, a pobreza e a criminalidade. Além disso, como ressaltado na introdução deste dossiê, os negros e mestiços eram sempre os portadores das características presentes nos distúrbios mentais. A solução? Regenerar a população, eliminando os degenerados:

Assim para a melhoria da raça poderia ser vantajoso cruzar com extranhos normaes os individuos francamente mestiços e degenerados quando haja esperança de regeneração da prole por esse meio; mas para os profundamente degenerados melhor seria deixa-los reproduzir entre si e extinguir-se a mesquinha geração por esterilidade e mortandade precoce resultante da progressiva decadencia. Dessa relação natural grande proveito resultaria para as famílias possuidoras de boas qualidades, as quaes se perpetuariam entre si, livres dos germes dos males que lhes innocularia a fatal mistura dos abastardados. Lucraria a espécie... (Gazeta Médica da Bahia, 1925, p. 161, citado por Schwarcz, 2002, p. 216)

Será possível encontrar elementos desta proposta eugênica da década de 20 no texto de Caplan de 1980? Creio que sim, quando o autor argumenta que, apesar de inúmeras tentativas e propostas de intervenção na população que poderá desenvolver distúrbios mentais, existirão aqueles indivíduos que se tornarão doentes, por características idiossincráticas, que não são passíveis de manipulação. 
Caplan não sugere que a Medicina impeça o cruzamento dos sadios com os doentes, nem apresenta uma intervenção orgânica naqueles que possuem genes portadores da degeneração. Mas, nem é preciso que o faça. Sua proposta não elimina os doentes. Estes serão excluídos de qualquer possibilidade de saúde porque o conhecimento científico produzido pela Medicina e, especialmente pela Psiquiatria, coloca-os como doentes em potencial e, portanto, sem qualquer possibilidade de ser outra coisa, se não aquela determinada pelo médico. $\mathrm{O}$ autor vai além do organicismo, uma vez que a eugenia é uma proposta política, fascista, que tem no organicismo uma mera justificativa pseudocientífica.

Conclui-se, desta maneira, que as idéias de Caplan só podem ser compreendidas ao se considerar os elementos preventivistas e organicistas presentes em seu conteúdo. Outros fatores, no entanto, são fundamentais para a análise do texto. A seguir, serão discutidos aqueles que o caracterizam como um discurso ideológico.

O conceito de ideologia, por sua vez, tal como proposto pelo materialismo histórico, possibilita uma crítica ao texto de Caplan. Segundo Chaú (2001a), o discurso ideológico é uma representação imaginária do real, que ocorre por meio dos princípios de abstração e inversão, no qual as contradições não são explicitadas. Quais as lacunas existentes no texto em questão?

A princípio, observa-se que ele transmite a idéia de que os indivíduos são os únicos responsáveis por sua condição de saúde ou doença e nascem inseridos em uma determinada classe social, porque naturalmente deve ser assim, como afirma o autor, ao falar sobre as condições de vulnerabilidade às quais estão submetidos alguns indivíduos.

Há duas questões a serem consideradas neste trecho. Em primeiro lugar, fatores como idade e sexo são tidos como equivalentes à classe socioeconômica, são inerentes ao indivíduo. Ou seja, a classe socioeconômica é dada com o nascimento, faz parte da constituição individual. A segunda questão diz respeito à idéia de destino e de imutabilidade da condição social. 
A Produção do Conhecimento Psicológico-Psiquiátrico em Saúde Mental...

Isto significa que, se algumas pessoas nasceram com menos possibilidades de humanizar-se, isto é um atributo do sujeito, como a cor de seus olhos; já está determinado desde que nasceu e, portanto, morrerá com ele. A não ser que tenha sorte e suas oportunidades de desenvolver-se como homem ocorram por meio da bondade de alguém ou dos conhecimentos psicológicos que poderão salvá-lo da inevitável condição de ser um doente mental!

O discurso articulado sobre a possibilidade de alguns adoecerem, e outros não, impede o questionamento sobre tais condições, uma vez que é possível fazer a correspondência proposta pelo autor. Assim, por uma rápida, imediata e simples observação, percebe-se que a população mais pobre, que possui menos recursos físicos, intelectuais e culturais (de acordo com padrões estabelecidos pela classe que domina) é a mais acometida por doenças, sejam mentais ou não. Logo, o raciocínio é imediato: estas pessoas têm mais chances de tornarem-se doentes; são doentes em potencial.

O que se oculta neste caso é o motivo desta situação. Não há o questionamento e a explicitação - porque se houvesse, não estaríamos falando de ideologia - das razões que tornam grande parte da população pobre também doente. Ocorre uma inversão: o efeito é tomado como causa, o determinante como determinado, o resultado como o início do processo. Assim, se os indivíduos possuem características favoráveis ou desfavoráveis, é esta condição que determinará sua possibilidade de serem saudáveis. Mas, como estas “características” foram produzidas? São elas que determinam a doença ou foram determinadas pela forma de organização da sociedade? Por que sempre há populações doentes, desviantes, anormais? A resposta seria simplesmente que é natural ser assim? Ou, ao contrário, que é importante para o funcionamento da lógica do capital que alguns sejam os responsáveis por sua doença e nunca se curem?

As próprias definições sobre os doentes já indicam quem serão os escolhidos para possuírem saúde. Os trechos de Caplan, destacados anteriormente, mostram que, independentemente de qualquer circunstância, as pessoas que vivem em ambientes instáveis, inadequados, desfavorecidos não 
poderão progredir. O fracasso social é determinado por suas condições idiossincráticas.

Outra lacuna encontrada neste discurso ideológico é a condição de produção da doença mental e a própria definição de anormalidade, comportamento desviante e problemático. O que é considerado como doença mental hoje, não o foi sempre. O conhecimento produzido pela Medicina e pela Psicologia sobre a doença mental é tomado como o determinante do processo histórico, ao invés de ser compreendido como determinado por ele. Isto significa que o conhecimento aparece sem vínculo com o contexto histórico e político no qual foi produzido.

Poderíamos também refletir sobre outras questões dissimuladas no discurso sobre o doente. A miséria de cada indivíduo aparece como miséria de condição e não de posição, como se as pessoas fossem doentes por sua condição desfavorável e, portanto, pobre. Oculta-se que a miséria é de posição na hierarquia da sociedade de classes.

Isto ilustra, ainda, como o entendimento da realidade se dá por meio da experiência imediata de quem produz este conhecimento psiquiátrico; trata-se do conceito de abstração presente no discurso ideológico. O que se observa é o dado aparente e imediato de que as pessoas que possuem a capacidade de resolver seus conflitos vivem em condições/sociedades favoráveis. Logo, aquelas que vivem em ambientes desfavoráveis não resolvem conflitos. Tem-se, assim, uma representação imaginária do real, que não pode ser compreendida somente como falsa ou ilusória, porque é ela que aparece como verdadeira à experiência imediata.

Todos os elementos constitutivos deste discurso ideológico ocultam as contradições presentes na sociedade de classes que produz e reproduz conflitos políticos e, portanto, de poder. As contradições são vistas como naturais e não como sociais. Estas podem ser observadas não só naquilo que denominamos de incoerências da própria articulação do discurso, mas também, e principalmente, no conflito inerente entre aquele que ocupa o lugar do saber e, assim, produz e organiza o conhecimento sobre aquele indivíduo analisado e julgado à luz da ciência. 
A Produção do Conhecimento Psicológico-Psiquiátrico em Saúde Mental...

Os aspectos levantados até este momento da análise sobre o texto de Caplan (1980) constituem-se como o desvelamento ou a explicitação de algumas lacunas do discurso ideológico sobre saúde/doença mental. Um outro conceito importante, sobre o qual o autor estrutura seu trabalho, é o de crise.

A crise é compreendida, dessa forma, como fator negativo, que desagrega, desarmoniza, mesmo considerando que possa trazer o crescimento da personalidade dos indivíduos. Todavia, deve-se questionar em qual sentido o conceito de crise pode ser definido como ideológico.

Segundo Chauí (2001a), geralmente, nos discursos oficiais dominantes, crise é entendida como descontinuidade, ruptura, desarmonia entre o que é aceitável para uma sociedade e a forma como os indivíduos pensam e agem. Rompe-se o funcionamento adequado das coisas e das idéias. Há uma relação entre o termo crise e desvio, e estas noções determinam como o mundo dever ser. Se houve uma crise, deixou-se de agir e pensar da forma comum, usual.

Caplan argumenta, em concordância com os discursos oficiais, que a crise psicológica é uma quebra do padrão de funcionamento dos indivíduos e pode ser benéfica quando as pessoas possuem condições favoráveis para lidarem com o desequilíbrio, ou causar sérios prejuízos, e até distúrbios mentais, quando o sujeito não possuir características que o levem à resolução do conflito. Nos dois casos, o desejável é que a crise seja resolvida, tenha uma solução.

Para Chauí (2001a), conceber a crise nestes termos faz parte de um determinado modo de pensamento, no qual a idéia de contradição não pode estar presente. Quando os conflitos ou as crises aparecem, são as contradições da sociedade que se manifestam. A contradição é expressa tanto na luta de classes, sobre a qual a sociedade capitalista se constituiu, como, neste caso específico, é expressa pela distância entre a possibilidade de saúde de uns e de doença de outros e pela própria idéia oculta de que alguns devem ficar doentes para que o funcionamento do todo se mantenha inalterado, dentro do padrão estabelecido por quem define critérios de normalidade. 


\title{
Aline Frollini Lunardelli Lara
}

\begin{abstract}
A crise é imaginada, então, como um movimento da irracionalidade que invade a racionalidade, gera desordem e caos e precisa ser conjurada para que a racionalidade anterior, ou outra nova, seja restaurada. A noção de crise permite representar a sociedade como invadida por contradições e, simultaneamente, tomálas como um acidente, um desarranjo, pois a harmonia é pressuposta como sendo de direito, reduzindo a crise a uma desordem fatual, provocada por enganos, voluntários ou involuntários, dos agentes sociais, ou por mau funcionamento de certas partes do todo (...) Tal representação permite, assim, imaginar o acontecimento histórico como um desvio. (Chauí, 2001a, p. 37)
\end{abstract}

Por que, então, é fundamental agir, com uma proposta de prevenção primária em saúde mental, com a finalidade de interromper a crise, tratar do indivíduo que vive o desequilíbrio? Quais são os objetivos de uma intervenção exatamente nos momentos de crise? Por que é necessário impedir que o conflito se estenda, provocando a desarmonia do padrão ideal de funcionamento?

Talvez porque a crise represente perigo. O perigo da explicitação das contradições, ou seja, se o conjunto dos indivíduos, se a coletividade "doente”, compreender que não é a portadora dos desvios, que não possui condições idiossincráticas prejudicadas ou desfavoráveis. A idéia de crise é tão combatida porque se ela for a manifestação das contradições da sociedade de classes, pode, de fato, haver o entendimento dos fatores que produzem as condições que oprimem muitos e favorecem poucos.

Não é por acaso que a noção de crise é privilegiada pelos discursos autoritários, reacionários, contra-revolucionários, pois neles essa noção funciona em dois registros diferentes, mas complementares. Por um lado, a noção de crise serve como explicação, isto é, como um saber para justificar teoricamente a emergência de um suposto irracional no coração da racionalidade: a "crise" serve para ocultar a crise verdadeira. Por outro lado, essa noção tem eficácia prática, pois é capaz de mobilizar os agentes sociais, acenando-lhes com o risco da perda da identidade coletiva, suscitando neles o medo de desagregação social e, portanto, o medo da revolução, oferecendo-lhes a oportunidade para restaurar uma ordem sem crise, graças à ação de alguns salvadores. (Chauí, 2001a, p. 37, itálico original)

Tratar a crise como algo negativo, desagregador, que acontece no e por causa do indivíduo é totalmente permitido em nossa sociedade para que o indivíduo seja contido. A crise é ruim para cada pessoa e é ela a responsá- 
A Produção do Conhecimento Psicológico-Psiquiátrico em Saúde Mental...

vel por sua condição crítica. Logo, o sujeito deve ser tratado e deve acreditar que ele é o seu pior agente patológico. O médico é sua possibilidade de cura. O doente deve ser submisso ao médico, mesmo porque, o "doutor" tem conhecimentos que ele não possui.

É o conhecimento científico a serviço da legitimação da impossibilidade de humanização dos indivíduos. É a justificativa dos motivos pelos quais a maioria das pessoas deve ocupar uma posição desprivilegiada na sociedade de classes. É preciso compreender, então, como a ciência se constitui no discurso capaz de determinar o lugar dos indivíduos na sociedade capitalista.

Por fim, façamos algumas considerações sobre o texto como discurso competente. Sabe-se que a ciência desempenha uma função fundamental na determinação das condutas humanas, pois produz conhecimentos sobre diversos aspectos da vida dos indivíduos, seja no âmbito da saúde, da educação, do trabalho, do direito, dentre outros. Todas as formas de relacionamento do homem com o contexto onde está inserido ocorrem por meio de vários discursos que orientam a maneira como ele deve agir pelo fato de ser um discurso competente (Chauí, 2001b).

Discurso competente significa que um conhecimento específico é legítimo e autorizado para falar sobre as coisas e sobre as pessoas. Desta maneira, não é o discurso do doente mental, mas sobre o doente mental, ou seja, não é o homem quem fala de si, mas alguém que fala sobre ele e, neste caso, o psiquiatra é autorizado a falar sobre os doentes mentais.

O texto de Caplan pode ser considerado como um exemplo do discurso competente produzido pela medicina psiquiátrica. Nele, os interlocutores já foram identificados pela separação daqueles que são competentes para falar sobre e daqueles que devem ouvir o que os competentes têm a dizer a respeito de si. O que é dito deve servir como a explicação mais precisa sobre as condutas humanas, com a finalidade de prevenir que algumas pessoas 
escolhidas sofram de distúrbios mentais. Também deve determinar quem serão aquelas que inevitavelmente adoecerão.

A que serve, então o discurso competente? Para Chauí (2001b), ele é o responsável pelo projeto de dominação e de intimidação social e política que é organizado por uma determinada classe social para conter outra.

Muitos conhecimentos são produzidos e autorizados a explicar o homem em suas diversas dimensões. O texto de Caplan é apenas um exemplo de um conteúdo autorizado e legítimo sobre saúde mental. Conteúdo que responsabiliza uma classe, possuidora da miséria de posição na hierarquia social, por sua doença e impossibilidade de cura, propondo um modelo de intervenção que um dia poderá alcançar seu objetivo máximo (como já ocorreu em outros momentos da história): o de eliminar barbaramente aqueles que desarmonizam o mundo em que vivemos. Ainda isto não será feito. Não desta maneira. Por enquanto, o objetivo é apenas produzir as condições que deixarão grande parcela dos homens à margem de qualquer possibilidade real de humanização ou, como neste caso, de saúde.

É fundamental considerar o fato de que estamos falando de uma situação de contradição. Nela reside a possibilidade de transformação que, neste momento histórico, se faz pela resistência à ordem existente. A resistência se constrói e se consolida também pela reflexão dos conteúdos produzidos pela Psicologia e por outros campos do conhecimento sobre saúde mental, desvelando o caráter opressor e justificador das desigualdades neles contido. Para tanto, é necessário construir outros discursos competentes essencialmente críticos e que assumam um novo posicionamento político e, exatamente por isso, sejam éticos.

Lara, A. F. L. (2006). The psychological production and psychiatric knowledge in mental health: considerations from an exemplar text. Psicologia USP, 17 (1), 35-52.

Abstract: This paper discusses the relation between ideology and the knowledge produced by psychiatry, for the purpose of uncover what is 
A Produção do Conhecimento Psicológico-Psiquiátrico em Saúde Mental...

occult in a text that is considered scientific. The analyzed material is concerned with primary prevention of psychic disturbs which produce "social inadaptation". The analysis is centered on the own concept of prevention as ideology, in a critical view that seeks the lacunas that guarantee and legitimate the State power of the ones who keep the hegemonic knowledge in the area of mental healthy.

Index terms: Psychiatry. Psychologia. Ideology. Mental helth. Social adjustment.

Lara, A. F. L. (2006). La construction des connaissances psychologiquespsychiatriques en santé mentale: des réflexions à partir d'un texte exemplaire. Psicologia USP, 17 (1), 35-52.

Résumé : Ce travail discute le rapport entre idéologie et les connaissances résultantes de la psychiatrie, afin de dévoiler ce qui est caché dans un texte considéré scientifique. Le matériel analysé traite de la prévention primaire aux désordres psychiques produisant le «dérèglement social ». L'analyse est centrée sur le concept même de prévention en tant qu'idéologie, dans une perspective critique cherchant les lacunes qui garantissent et qui légitiment le pouvoir politique de ceux qui détiennent les connaissances hégémoniques dans le domaine de la santé mentale.

Mots-clés: Psychiatrie. Psycologie. Idéologie. Santé mentale. Adaptation sociale.

\section{Referências}

Caplan, G. (1980). Um modelo conceptual para prevenção primária. In G. Caplan, Princípios de Psiquiatria preventiva (pp. 40-69). Rio de Janeiro: Zahar.

Chauí, M. (2001a). Crítica e ideologia. In M. Chauí, Cultura e democracia: o discurso competente e outras falas (9a ed., pp. 15-38). São Paulo: Cortez.

Chauí, M. (2001b). O discurso competente. In M. Chauí, Cultura e democracia: o discurso competente e outras falas (9a ed., pp. 3-13). São Paulo: Cortez.

Chauí, M. (2003). O que é ideologia? São Paulo: Brasiliense. 


\section{Aline Frollini Lunardelli Lara}

Costa, J. F. (1989a). Prefácio a esta edição. In J. F. Costa, História da Psiquiatria no Brasil: um corte ideológico (4a ed. rev. e ampl., pp. 9-20). Rio de Janeiro: Xenon, 1989.

Costa, J. F. (1989b). Psiquiatria preventiva e representação da doença mental. In J. F. Costa, História da Psiquiatria no Brasil: um corte ideológico (4a ed. rev. e ampl., pp. 21-38). Rio de Janeiro: Xenon.

Felix, R. H. (1980). Apresentação. In G. Caplan, Princípios de Psiquiatria preventiva (p. 9). Rio de Janeiro: Zahar.

Ferreira, A. B. de H. (1963). Pequeno dicionário da Língua Portuguesa (10a ed.). Rio de Janeiro: Civilização Brasileira.

Schwarcz, L. M. (2002). As faculdades de medicina ou como sanar um país doente. In L. M. Schwarcz, O espetáculo das raças: cientistas, instituições e a questão racial no Brasil - 19870-1930 (pp. 189-238). São Paulo: Companhia das Letras.

Recebido em: 24.03.2006

Aceito em: 3.04.2006 